\title{
Spinal Epidural varicosity resembling prolapsed intervertebral disc on MRI:A diagnostic dilemma for lumbar canal stenosis
}

\begin{abstract}
Sciatica is generally caused by such well-recognized entity as lumbar disc herniation in neurosurgical practice. However rare pathologies such as epidural varices may mimic them by causing radicular symptoms. In this case report, we present a 20 -years-old man with the complaint of low back pain and bilateral sciatica $(\mathrm{Lt}>\mathrm{Rt}) \&$ neurogenic claudication who was operated for right L5-S1 disc herniation. The lesion interpreted as an extruded disc herniation preoperatively on MRI but was found to be an epidural varix compressing the nerve roots intraoperatively. The varicosity of veins was found in epidural space causing canal stenosis.
\end{abstract}

Volume II Issue I - 202I

\author{
Vijay Kumar Raut,' Akhlaque Hossain Khan,' \\ Mamun Ahmad,' Sumit Barua,' Nazmin \\ Ahmed,' Shahidul Islam Khan, ${ }^{2}$ Nwoshin \\ Jahan,' Bipin Chaurasia' \\ 'Department of Neurosurgery, Bangabandhu Sheikh Mujib \\ Medical University, Bangladesh \\ ${ }^{2}$ Department of Orthopaedic, Bangabandhu Sheikh Mujib \\ Medical University, Bangladesh
}

Correspondence: Bipin Chaurasia, Chief resident Department of Neurosurgery, Bangabandhu Sheikh Mujib Medical University, Dhaka, Bangladesh, Email trozexa@gmail.com

Received: May 25, 2020 | Published: February 18, 2021

\section{Introduction}

Epidural varices in the lumbar spine are acquired lesions that are caused by dilation of the internal vertebral venous plexus. They are often accompanied by dilation of intervertebral veins and external vertebral venous plexus. The dilated veins in the epidural spaces or in the intervertebral foramina cause irritation or compression of the thecal sac and nerve roots, which results in lumbar radiculopathy. $\&$ neurogenic claudication. ${ }^{1-4}$ Epidural venous plexus enlargement, presenting with low back pain and radiculopathy, is an uncommon cause of nerve roots impingement. This condition commonly mimics a herniated nucleus pulposus radiologically. The radiological diagnosis is often missed and the diagnosis is made during the surgery. It is estimated at $4.5 \%$ of operations for lumbar disc herniation. ${ }^{5,6}$ Epidural varices mimicking intervertebral disc prolapse can cause features of lumbar canal stenosis.Symptomatic epidural varices presenting with radiculopathy is extremely rare and was first reported by Cohen

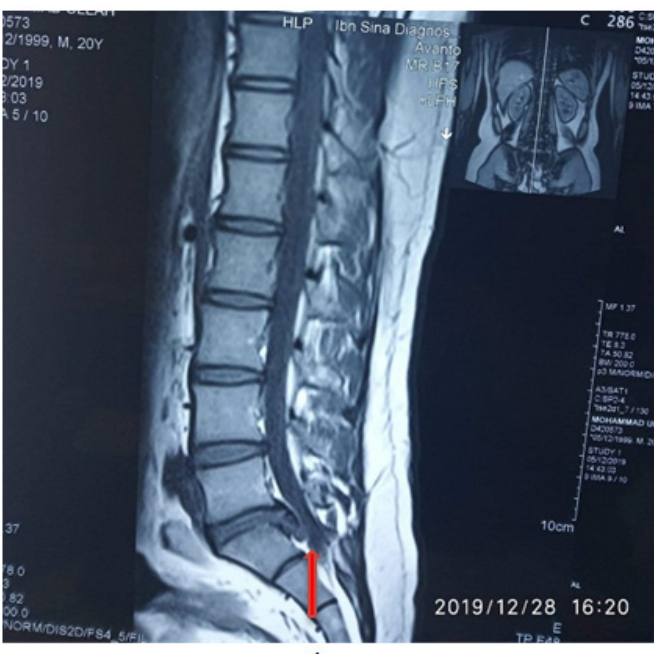

A and Epstein in the 1940s. Gumbel et al reported an incidence of $0.5 \%$ of isolated nerve root compression caused by varices among 1091 cases of sciatica. The pathogenesis of epidural varices has not been fully established, possible underlying etiologies that may result in symptomatic epidural varices include vascular anomalies, superior or inferior vena cava thrombosis, Budd-Chiari syndrome, intracranial hypotension, pregnancy and portal hypertension. ${ }^{6-8}$

\section{Case summary}

A twenty years old male presented in outpatient department with history of low back pain, bilateral sciatica (left $>$ right), neurogenic claudication for one month. Bowel \& bladder functions were normal. On examination patient had limited SLR on left side with 20 degrees $\& 60$ degrees on right side. Sensory \& motor functions were normal. Baseline investigations were done along with X- ray lumbosacral spine, MRI lumbosacral spine with MR Myelogram.

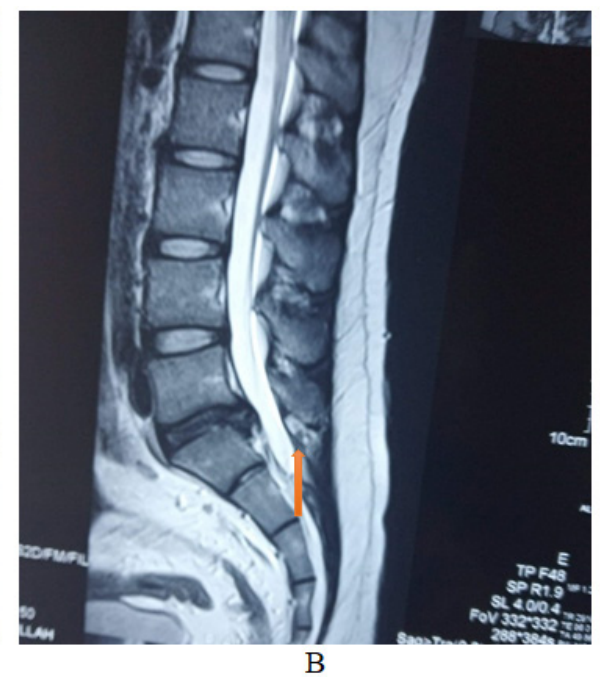




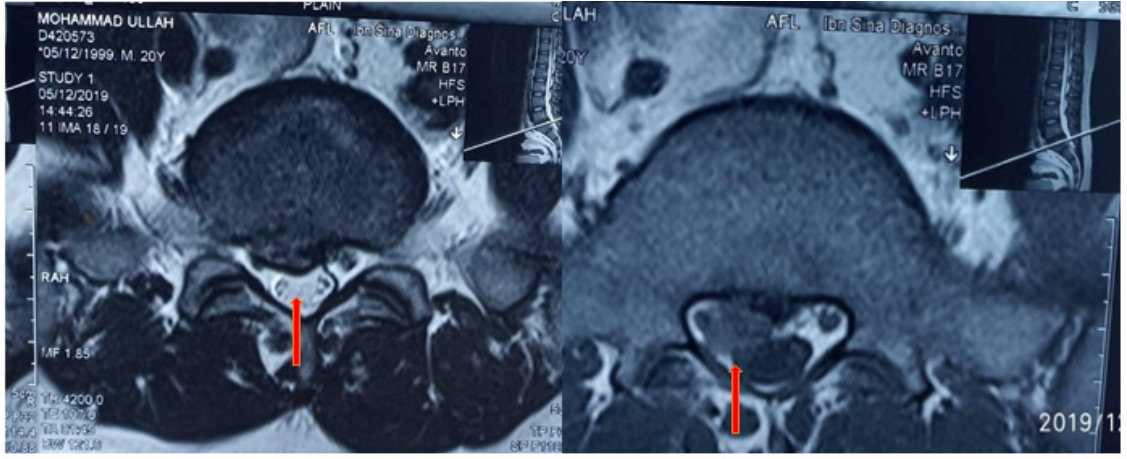

C

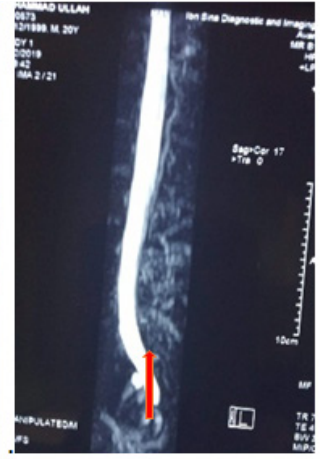

D

Figure I A-D shows mri of lumbosacral spine tiw sagittal \& $t 2 w$ sagittal \& axial view (key film).

Arrow on films reprsinting the venous plexus that resembling herniated disc at $\mid 5$-s $\mid$ level. The venous plexus causing canal stenosis at same level (c)\& mr myelogram (d) arrow showing globular hyperintensity attched with thecal sac.

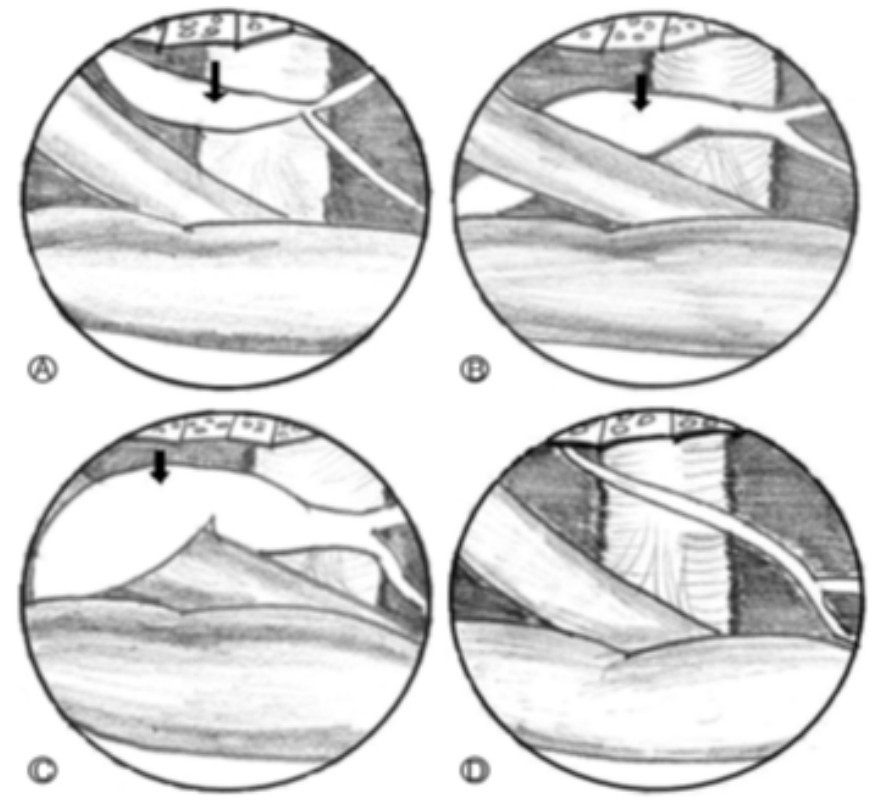

Figure 2 (A-D) Pattern of epidural varicosity in operative field (schematic illustration). Veins dilated but do not compress nerve root (A; Type A). Veins dilated and located anterolaterally and compress nerve root (B; Type B). Veins dilated and encircled nerve root and compress it (C; Type $C)$. Type $N$ is normal anatomical structures with no varices exist (D). Venous varicosity (arrows). ${ }^{3}$
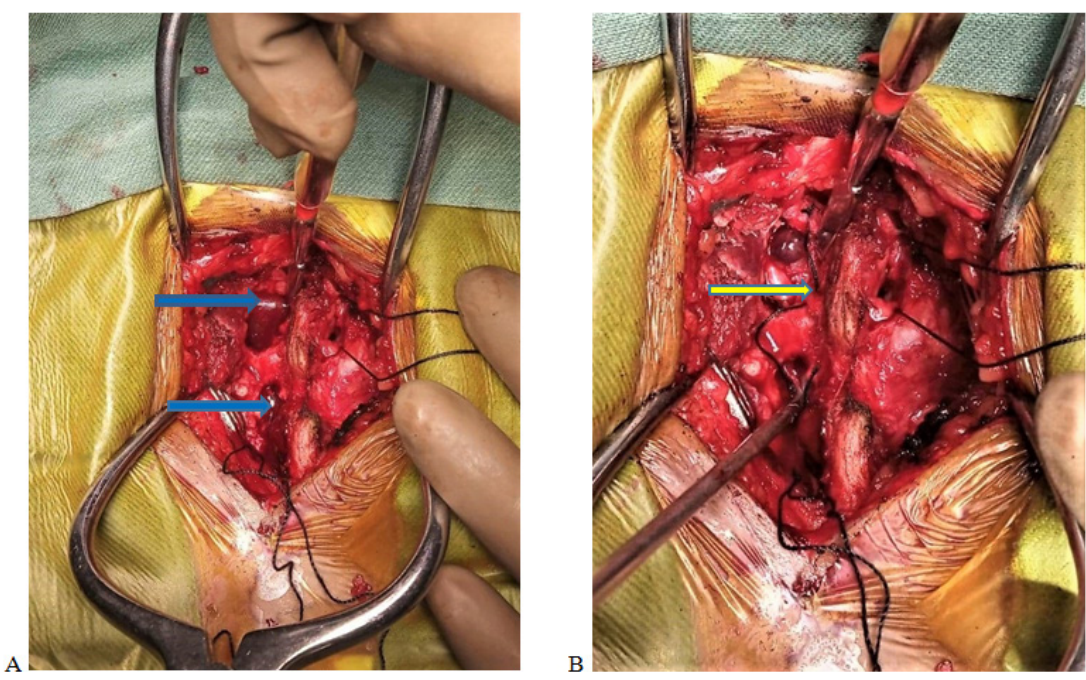

Figure 3 A\&B shows epidural venous plexus (A) \& type C pattern of venous varicosity pushing nerve root laterally (B), encircling root in cranio-caudal direction \& compressing thecal sac. Blue arrow pointing venous varices \& yellow arrow pointing nerve root.

Citation: Raut VK, Khan AH,Ahmad M, et al. Spinal Epidural varicosity resembling prolapsed intervertebral disc on MRI:A diagnostic dilemma for lumbar canal stenosis.J Neurol Stroke. 202 I; I ( I):23-25. DOI: I0.15406/jnsk.202I.I I.00449 


\section{Discussion}

Jeong-Hyuk et al has shown that Epidural venous varicosity can be classified into four types based on the relationship between epidural venous varicosity (varices) and nerve structures. Type $\mathrm{N}$ is normal anatomical structures with no varices exist. Cases in which varices exist were divided into three types based on the appearance of varices. Type A is conditions in which epidural veins are dilated but located parallel to the nerve root on the lateral side of the nerve root and thus do not compress the nerve root. Type $\mathrm{B}$ is conditions in which varices are located on the anterior lateral side of the nerve root to compress the nerve root. Type $\mathrm{C}$ is conditions in which varices are encircled around the nerve root and compressing the nerve root. ${ }^{3}$

As in our case, the preoperative diagnosis was presumed a case of canal stenosis due to centrally herniated disc at L5-S1 level by history, clinical examinations \& radiological investigations. Patient was planned for conventional discectomy at L5/S1 level on torso flat prone position with torso on hall frame, abdomen hanging free \& hip flexed. After having fenestration done, a plexus of tortuous veins was found in epidural space at L5/S1 level on right side. Nerve root on right side was pushed laterally by varices. Canal was decompressed by punching out ligamentum flavum \& discectomy on left side. Postoperatively the radicular pain didn't subsided satisfactorily hence Resection of varices was planned for second setting after having proper evaluation \& investigations of venous varicosity.

Our aim to publish this article not to focus on treatment modalities but mainly to focus on that the features of radiculopathy \& neurogenic claudication may arise due to compression of theca sac \& nerve root by epidural varices. Radiologically may resemble herniated disc, such diagnostic dilemma of canal stenosis on radiology may be surprising intraoperatively sometimes like in our case. ${ }^{4-9}$ Every neurosurgeon should be careful regarding this issue that all radiculopathy or neurogenic claudication are not due to herniated disc which resembles like disc on MRI.

\section{Conclusion}

An abnormal dilated epidural venous plexus that resembles aherniated lumbar disc on MRI is a rare entity. This uncommon condition should be always kept in mind during lumbar disc surgery. Preoperative misdiagnosis is common; Sometimes Radiological diagnosis can be surprising during surgery. Proper evaluation of pathology prior to coagulative ablation is usually main stay of treatment for epidural varices.

\section{Declaration}

\section{Consent for publication}

An informed written consent was obtained from the patient.

\section{Funding}

This research did not receive any specific grant from funding agencies in the public, commercial, or not-for-profit sectors.

\section{Authors contribution}

Conception, Diagnosis and design, Radiological diagnosis and Final approval of manuscript: Bipin Chaurasia, Manuscript preparation, Technical revision, Maunscript editing and revision: Akhalaque Hossain Khan, Vijay Kumar Raut, Mamun Ahmad, Sudip Barua, Literature search: Nazmin Ahmad, Shahidul Islam Khan.

\section{Acknowledgments}

None.

\section{Conflicts of interest}

The authors declare no conflicts of interest.

\section{References}

1. Bursalı A, Akyoldas G, Guvenal AB, et al. Lumbar epidural varix mimicking disc herniation. J Korean Neurosurg Soc. 2016;59(4):410.

2. Donmez FY. Epidural venous plexus engorgement: what lies beneath? Case reports in radiology. 2015;2015.

3. Jeong HJ, Sim WS, Park HJ, et al. Severe lumbar radiculopathy with epidural venous plexus engorgement in a morbidly obese pediatric patient: A case report. Medicine. 2019;98(33):e16842.

4. Ju JH, Ha HG, Jung CK, et al. Patterns of epidural venous varicosity in lumbar stenosis. Korean J Spine. 2012;9(3):244.

5. Paksoy Y, Gormus N. Epidural venous plexus enlargements presenting with radiculopathy and back pain in patients with inferior vena cava obstruction or occlusion. Spine. 2004;29(21):2419-2424.

6. Raghavendra V, Haridas P, Anand Kumar AK. Spinal Epidural Varices, a great Mimic of Intervertebral Disc Prolapse-A Case Series. J Orthop Case Rep. 2014;4(4):3.

7. Kogias E, Kircher A, Deininger MH, et al. A very rare cause of low-back pain and sciatica: deep vein thrombosis due to absence of the inferior vena cava mimicking the clinical and radiological signs of lumbar disc herniation: Case report. J of Neurosurg Spine. 2011;15(2):164-167.

8. Slin'ko EI, Al-Qashqish II. Surgical treatment of lumbar epidural varices. J Neurosurg Spine. 2006;5(5):414-423.

9. Ahsan K, Hasan S, Khan SI, et al. Conservative versus operative management of postoperative lumbar discitis. J Craniovertebr Junction Spine. 2020;11(3):198. 